\title{
Relações de gênero e memórias das ditaduras civis-militares: perspectivas da historiografia francesa sobre o Cone Sul
}

\author{
Gender relations and memories of civil-military dictatorships: perspectives of French \\ historiography on the Southern Cone \\ Janine Gomes da Silva \\ https://orcid.org/0000-0003-2866-2981 \\ Universidade Federal de Santa Catarina
}

\begin{abstract}
Resumo: Nos últimos anos temos visto um aumento significativo dos estudos que problematizam as histórias e memórias relacionadas ao período das ditaduras civismilitares no Cone Sul (Argentina, Brasil, Bolívia, Chile, Paraguai e Uruguai). De diferentes maneiras, o fim das ditaduras que ocorreram nas décadas de 1960, 1970 e 1980 têm possibilitado várias pesquisas, principalmente problematizando a construção de uma memória sobre esse passado. $E$, as questões de gênero e a violência de gênero também são temas presentes nestes estudos. Nos últimos anos fui percebendo o interesse de historiadoras/es, especialmente franceses, nos estudos sobre as ditaduras civis-militares que ocorreram no Cone Sul. Percebi o quanto os temas relacionando gênero, memória e ditaduras nos países deste continente tem sido alvo de distintas abordagens e chamou-me a atenção os enfoques metodológicos das/os pesquisadoras/es europeus para as histórias do Cone Sul.
\end{abstract}

Palavras-chave: Gênero. Historiografia. Ditaduras no Cone Sul. Abstract: In recent years we have seen a significant increase in studies that
problematize the stories and memories related to the period of civil-military dictatorships
in the Southern Cone (Argentina, Brazil, Bolivia, Chile, Paraguay and Uruguay). In
different ways, the end of the dictatorships that took place in the 1960s, 1970s and 1980s
has made possible several investigations, mainly problematizing the construction of a
memory about this past. And, gender issues and gender violence are also themes
present in these studies. In recent years, I have noticed the interest of historians,
especially French, in studies of the civil-military dictatorships that took place in the
Southern Cone. I saw how the themes relating gender, memory and dictatorships in the
countries of this continent have been the target of different approaches and I drew
attention to the methodological approaches of European researchers to the histories of
the Southern Cone.

Keywords: Gender. Historiography. Dictatorships in the Southern Cone.

Nos últimos anos temos visto um aumento significativo dos estudos que problematizam as histórias e memórias relacionadas ao período das ditaduras civismilitares no Cone Sul (Argentina, Brasil, Bolívia, Chile, Paraguai e Uruguai). De diferentes maneiras, o fim das ditaduras que ocorreram nas décadas de 1960, 1970 e 1980 têm possibilitado várias pesquisas, principalmente problematizando a construção de uma memória sobre esse passado. Nestes países, temos acompanhado um crescimento dos estudos sobre esta temática, todavia, para além do Cone Sul, outras/os pesquisadoras/es tem se interessado por compreender estes diferentes processos ditatoriais. Historiadores do Norte tem se preocupado em buscar construir narrativas

Esta obra está licenciada sob uma Creative Commons - Atribuição 4.0 Internacional 
sobre estas histórias e, deste interesse de pesquisa, podemos procurar conhecer algumas perspectivas, como por exemplo, a partir da historiografia francesa.

Deste modo, uma possibilidade é perceber como a historiografia francesa vem tematizando o período que compreende as ditaduras civis-militares vivenciadas no Cone Sul, articulado com memórias e relações de gênero. Neste sentido, uma questão emerge: a historiografia francesa tem feito pesquisa articulando gênero, memória e ditaduras no Cone Sul? O que podemos observar é que esta temática é muito recente. Sim, há muita pesquisa publicada, principalmente sobre memória, e também sobre gênero e ditaduras. Mas, podemos dizer, a articulação destas três categorias ainda é tímida. Se observarmos o que se publica nos países do Cone Sul, podemos encontrar muitas citações da historiografia francesa, inclusive em trabalhos que juntam estas três temáticas. Mas, na historiografia francesa, isso é relativamente recente e raro. Assim, mesmo quando nos interessamos por esta historiografia, cabe notar que esta questão no Cone Sul já vem sendo discutida de forma mais ampla e, desta maneira, é importante acompanhar esta trajetória, especialmente no Brasil, antes de focalizar o que tem sido publicado na França.

Neste artigo apresentamos algumas reflexões que esperamos, possam contribuir com as análises sobre este assunto, buscando compreender alguns aspectos de como a historiografia francesa vem contribuindo com este debate, seja publicando obras sobre estas ditaduras, ou ainda, influenciando as pesquisas realizadas nos países do Cone Sul. Assim, neste texto pretendemos: 1) mostrar como estão os estudos sobre gênero, memórias e ditaduras no Cone Sul, especialmente no Brasil; 2) apresentar o levantamento feito, os acervos pesquisados e os resultados do que localizamos na França; e, 3) discorrer sobre algumas pesquisas, publicadas na França, que focalizam gênero, memória e ditaduras em países do Cone Sul.

\section{Gênero, memórias e ditaduras no Cone Sul}

Como mencionamos, temos visto um aumento significativo dos estudos que problematizam as histórias e memórias relacionadas ao período das ditaduras e, deste mesmo modo, as lutas pela memória se fazem presentes. Em 2014, na historiografia brasileira, as rememorações em torno dos 50 anos do golpe civil-militar no Brasil foi tema de livros, dossiês de revistas científicas e de eventos acadêmicos que de diferentes maneiras evidenciaram as memórias relacionadas a este período ${ }^{1}$. Estas memórias, mais do que destacar fatos relacionados ao período, também visibilizam as disputas sobre versões e a luta pela memória. E, falar em memória em disputa significa também lembrar a dimensão política da memória, pois, de acordo com a argentina Pilar Calveiro:

Las memorias son siempre plurales porque comportan interpretaciones también plurales de lo vivido pero, sobre todo, de sus significados para la acción presente, es decir, para la política. Al conectar la experiencia del passado con la actual, la acción pasada con la presente, las prácticas de la memoria son acto y ejercicio compartido, una de cuyas dimensiones es la reflexión teórica o académica. (2012,

\footnotetext{
${ }^{1}$ Dentre estes eventos gostaria de destacar o evento que organizamos na Universidade Federal de Santa Catarina - UFSC. Trata-se do XV Encontro Estadual de História da ANPUH-SC e II Colóquio Internacional Gênero, Feminismos e Ditaduras no Cone Sul, que teve como tema "1964-2014: Memórias, Testemunhos e Estado", que contou também com pesquisadoras/es da Argentina, Chile e Uruguai. Programação disponível em: http://www.encontro2014.sc.anpuh.org/site/capa Acesso em: 25/maio/2019.
} 
Assim, dentre as várias possibilidades para perspectivar este período, gostaria de sublinhar a reflexão teórica sobre esta gestão do passado, que permeia também a historiografia dos e sobre os países do Cone Sul. De diferentes maneiras, o fim das ditaduras que ocorreram na Argentina, Brasil, Bolívia, Chile, Paraguai e Uruguai ${ }^{2}$ têm $^{2}$ possibilitado várias pesquisas, principalmente analisando a construção de uma memória sobre esse passado que não se deve esquecer e que não se quer repetir. Especialmente sobre a Argentina destaca-se o trabalho de Elizabeth Jelin, que vem inspirando pesquisas no campo da memória em outros países do Cone Sul ${ }^{3}$.

E, sobre a ditadura civil-militar vivenciada no Brasil a bibliografia é extensa ${ }^{4}$, mas, gostaria de destacar também as abordagens que de maneira inovadora vem problematizando as histórias deste período articulando as relações de gênero ${ }^{5}$. Em "Gênero, feminismos e ditaduras do Cone Sul", Joana Maria Pedro e Cristina Scheibe Wolff (2010), apresentam para o público brasileiro as análises de várias pesquisadoras que vem trabalhando com esta temática nos diferentes países do Cone Sul. Os capítulos do livro são frutos de trabalhos apresentados no Colóquio Internacional com o mesmo tema, realizado na Universidade Federal de Santa Catarina em 2009, que tinha como objetivo,

[...] constituir uma rede de pesquisadoras/es envolvidas com a pesquisa e recuperação da história recente no Cone Sul sobre a temática Gênero, feminismos e ditaduras, produzindo na troca e exposição dos trabalhos, um momento de debate e produção original de conhecimentos sobre a temática. (PEDRO, WOLFF, 2010, p. 7)

Ainda referente ao Brasil, destacam-se os trabalhos desenvolvidos pela Comissão Nacional da Verdade (CNV) que foi criada pela Lei 12.528/2011 e instituída em 16 de maio de 2012 e tem por finalidade "apurar graves violações de Direitos Humanos ocorridas entre 18 de setembro de 1946 e 5 de outubro de 1988”. A criação da CNV representa um marco na nossa relação com o passado da ditadura. Mas, alguns aspectos chamam a atenção, especialmente, o fato de abarcar um período anterior à ditadura civil-militar (que começou em 1964), ter um caráter tardio em relação à criação das demais comissões criadas nos países do Cone Sul e não ter "caráter jurisdicional ou persecutório". Antes da criação desta lei, outras medidas foram tomadas, como a Lei dos Desaparecidos (1995) $)^{7}$ e a lei da Comissão de Anistia (2002) ${ }^{8}$.

Em relação às pesquisas que desenvolvemos na Universidade Federal de Santa Catarina, destaca-se que desde março de 2004, uma equipe de pesquisadoras/es do

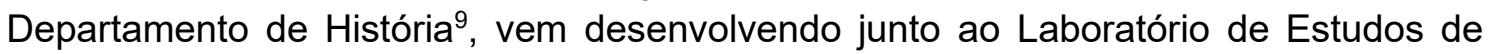

2 Ditaduras no Cone Sul: Argentina (1966/1973 e 1976/1983); Bolívia (1964/1982 com algumas interrupções); Brasil (1964/1985); Chile (1973/1988-1990); Paraguai (1954/1989); e, Uruguai (1973/1985).

${ }^{3}$ Destaca-se especialmente a coleção Memorias de la Represión, publicada pela Siglo XXI Editores, em 12 volumes.

${ }^{4}$ Muitos são os trabalhos sobre o tema da ditadura militar no Brasil, dentre eles destaco: Fico, 2014 a e 2014 b; Gaspari, 2002; Joffily, 2008; Padrós, Barbosa, Lopez, Fernandes, 2014; Rodeghero, Montenegro, Araujo, 2012; Quadrat, 2011; Santos, Teles, teles, 2009.

${ }^{5}$ Entre eles, destacam-se: Pedro, Wolff, 2010; e, Pedro, Wolff, Veiga, 2011.

${ }^{6}$ Lei n. 12.528, de 18 nov. 2011. Disponível em: http://cnv.memoriasreveladas.gov.br/institucional-acessoinformacao/a-cnv/56-conheca-a-lei-que-criou-a-comissao-nacional-da-verdade.html Acesso em: 25/maio/2019.

${ }^{7}$ Lei n. 9.140, de 4 dez. 1995.

8 Lei n. 10.559, de 13 nov. 2002.

9 Professoras Cristina Scheibe Wolff, Joana Maria Pedro e Roselane Neckel, juntamente com bolsistas de 
Gênero e História - LEGH, pesquisas que tematizam o período das ditaduras civismilitares no Cone Sul ${ }^{10}$. Estas pesquisas, inicialmente, procuraram constituir uma narrativa histórica sobre o período de ressurgimento do movimento feminista no Brasil, chamado de "Segunda Onda", a partir de meados dos anos 1970, focalizando a maneira como, apesar da ditadura e dos preconceitos antifeministas, muitas mulheres e alguns homens começaram a se pensar como feministas no período de 1964 a 1985. Para tanto mapearam a maneira como estas ideias circularam; perceberam como foi o contato com a circulação de ideias do feminismo a nível nacional e internacional; observaram os livros que o estavam divulgando; perceberam a participação em movimentos sociais e o contato com pessoas que influenciaram no sentido de constituir uma identificação com o feminismo. Todo o material coletado sobre o feminismo no Brasil, Argentina, Paraguai, Uruguai, Bolívia e Chile, a partir de diferentes pesquisas, vem propiciando várias análises, possibilitando um estudo comparativo com outros países, em especial aqueles do Cone Sul, que, como o Brasil, viveram períodos de ditaduras. Nesta comparação, observam-se como se constituíram os vários grupos feministas, como atuaram, suas relações com as ditaduras e os movimentos de resistência a estas, seus processos de constituição de identificação e de diferença, entre outros temas.

Com a publicação de vários trabalhos, esta equipe vem contribuindo com diferentes reflexões sobre o período das ditaduras militares no Cone Sul e, ao mesmo tempo, acumulando um extenso acervo (coleção de documentos, livros, periódicos, entrevistas realizadas a partir da metodologia da história oral, fotografias, entre outros). Neste momento, a documentação pesquisada pela equipe do LEGH apresenta uma mostra de diferentes tipos documentais que foram produzidos pelas ditaduras do Cone Sul.

A partir de 2011, começamos a trabalhar também com o acervo destas pesquisas. Assim, além de trabalhar com as questões de gênero presentes nas pesquisas ${ }^{11}$, a diversidade da documentação abrigada no LEGH despertou o interesse em problematizar como estas fontes, de diferentes maneiras, podem contribuir para uma reflexão no campo da memória e do patrimônio, especialmente documental. Deste interesse, surgiu a preocupação em não tratar apenas das Coleções formadas pela pesquisa referentes aos acervos das ditaduras do Cone Sul, mas, perspectivar a forma como diferentes acervos possibilitam narrativas para o tema das ditaduras ocorridas na América do Sul. Neste sentido, começamos a organizar a documentação com vistas a disponibilizá-la no Repositório Digital da UFSC ${ }^{12}$, contribuindo com outras/os pesquisadoras/es sobre o tema e também iniciamos um projeto de pesquisa especialmente sobre espaços de memória do Brasil e do Paraguai ${ }^{13}$. Este projeto tinha como objetivo investigar como os arquivos que abrigam a documentação sobre as ditaduras militares no Brasil e no Paraguai se constituem como espaços de memória que podem (re)significar a história contemporânea do Cone Sul, procurando estabelecer relações no campo da memória e do patrimônio. Com esta pesquisa, aprofundamos

\footnotetext{
Iniciação Científica, mestrandas/os e doutorandas/os.

${ }^{10}$ Destaca-se que este breve histórico sobre as atividades do LEGH, foi anteriormente publicado, ver: Silva, Pedro, Wolff, 2018.

11 Sobre gênero e feminismos no Cone Sul, ver: Pedro, 2010.

12 No momento estamos trabalhando na organização de toda a documentação para disponibilizar no Repositório Institucional (RI) da Universidade Federal de Santa Catarina (UFSC), que tem como missão "armazenar, preservar, divulgar e oferecer acesso a produção científica e institucional da UFSC". Disponível em: http://www.repositorio.ufsc.br. Acesso em: 25/maio/2019.

13 Projeto de Pesquisa "Espaços de memória. Arquivos e fontes documentais: (re)significando as ditaduras militares (Brasil e Paraguai)", encerrado em 2015, financiado pelo CNPq.
} 
nossas observações para a documentação do Archivo del Terror, em Assunção, no Paraguai e para os arquivos do Cone Sul e a ampliamos nossos olhares para as pesquisas que tematizam as questões de gênero no Cone Sul ${ }^{14}$ e sobre a historiografia e espaços de memória, além do Brasil e Paraguai, do Chile e Argentina. Chamado de Archivo del Terror, desde que foi "descoberto" em 22 de dezembro de 1992, este arquivo oficialmente é o Centro de Documentación y Archivo para la Defensa de los Derechos Humanos que funciona junto ao Museo de la Justicia.

Este espaço se apresenta como um espaço de memória da ditadura que o país viveu de 1954 a 1989, sob o comando de Alfredo Stroessner e procura "promover a recuperação da memória histórica cidadã" (Corte Suprema de Justicia, 2010). Seu acervo abriga diferentes documentos da inteligência paraguaia e as comunicações das autoridades paraguaias policiais e militares, bem como, documentos da chamada "Operação Condor" ${ }^{15}$, contendo informações sobre outras ditaduras do Cone Sul, como da Argentina, Chile e Brasil. Este acervo documental (que inclui documentos comprobatórios de violação de direitos humanos) é considerado por muitos pesquisadores como um dos mais volumosos dos anos de repressão na América do Sul e sua descoberta, bem como, os usos políticos a partir dele, são chamados de "papéis que ressignificaram a memória do stronismo" (PAZ, AGUILAR, SALERNO, 2008). A ditadura de Stroessner é considerada uma das mais violentas do Cone Sul e o impacto da descoberta do Archivo del Terror extrapola às discussões sobre a história da ditadura naquele país, mas infere para as ditaduras em outros lugares da América do Sul.

Aos poucos, além do objetivo inicial da pesquisa, nos deparamos com uma rica discussão também acerca das Comissões da Verdade instituídas nestes países e com a questão da violência de gênero nestas ditaduras. Evidentemente cada país encaminhou de maneira diferente suas questões políticas sobre os períodos de ditadura, mas, de maneira geral, estamos acompanhando o debate sobre os significados "para la acción presente, es decir, para la política”, como diria Calveiro (2012, p. 21). E, foi acompanhando este debate e desenvolvendo a pesquisa que, aos poucos, fomos ampliando nossos olhares para as histórias das ditaduras de outros países do Cone Sul, como o Chile e Argentina. Ainda sobre o Chile, destaco as análises de Nelly Richard (2008), especialmente quando mostra a força do feminismo na ação política contra a ditadura e Loreto Rebolledo (2008), ao tematizar a questão do exílio.

Nas diferentes pesquisas analisadas sobre o "tempo das ditaduras" nos países do Cone Sul, temas como clandestinidade, exílio, desparecimentos e a questão da tortura emergem. Nem sempre estas temáticas articulam gênero nas análises sobre memórias e ditaduras, mas, podemos observar, que cada vez mais historiadoras/es destes países vem investindo nesta articulação. O passado recente, assombrado pelo terrorismo de estado, é alvo de várias investigações, pois, o medo, naqueles tempos sombrios, fez parte da história do Cone Sul. As estratégias usadas pelo terrorismo de Estado foram variadas e, de acordo com Caroline Silveira Bauer,

Por 'estratégia de implantação do terror' entende-se o conjunto das práticas de sequestro, tortura, morte e desaparecimento, assim como a censura e a desinformação e suas consequências, principalmente a formação da 'cultura do medo'. Essa estratégia pode ser entendida como 'projetos', em seu sentido

\footnotetext{
${ }^{14}$ Destaco especialmente os trabalhos de Oberti, 2010; e, sapriza, 2010.

15 Operação de Inteligência criada no Chile, com o apoio da Argentina, Brasil, Bolívia, Paraguai e Uruguai que perseguia militantes de esquerda oriundos de qualquer um destes países, onde estivessem. Ver, Vera (2002).
} 
consciente e racional, pois o terror, como forma de dominação política, foi uma 'opção' dos civis e militares responsáveis pelas ditaduras e não uma 'fatalidade' ou 'imposição' conjunturais. (2012, p. 31)

Estima-se que no período que o terrorismo de Estado assolou o Cone Sul, "desapareceram aproximadamente 90 mil pessoas, entre argentinos, chilenos, uruguaios e brasileiros" (BAUER, 2012, p. 29). No Brasil, oficialmente foram 434 casos de mortos e desaparecidos políticos ${ }^{16}$.

São vários os trabalhos sobre estes países e estes são apenas alguns exemplos de como, na historiografia do Cone Sul, a articulação entre gênero, memória e ditaduras muitas vezes se faz presente, desde a primeira década do século $X X$.

\section{Notas sobre gênero, memória e ditaduras na historiografia francesa}

As pesquisas sobre as ditaduras no Cone Sul nos possibilitaram contato com diferentes pesquisadores europeus, ligados a Centros de Pesquisa que tematizam a América Latina, e percebi o quanto os temas relacionando gênero, memória e ditaduras nos países deste continente tem sido alvo de distintas abordagens e chamou-me a atenção os enfoques metodológicos das/os pesquisadoras/es europeus para as histórias do Cone Sul. Destaca-se por exemplo os trabalhos publicados na Revista Nuevo Mundo, Mundos Nuevo, em dossiê sobre Femmes dans les Amériques ${ }^{17}$.

Desta forma, iniciamos uma nova pesquisa objetivando conhecer as metodologias e estabelecer comparações com a historiografia francesa que tem se preocupado com os estudos no campo das relações de gênero e da memória, visando investigar como esta historiografia vem tematizando (em uma perspectiva comparativa entre Norte e América do Sul) o período que compreende as ditaduras civis-militares vivenciadas no Cone Sul, especialmente Brasil, Paraguai, Chile e Argentina. A questão de gênero na pesquisa também está presente por perceber que é no campo dos estudos de gênero que tem surgido análises interessantes de pesquisadores europeus, especialmente ligados ao Institut des Amériques, na França, como por exemplo, as pesquisas do historiador Luc Capdevila, um estudioso sobre a história do Paraguai ${ }^{18}$, que com Claire Sorin, apresentou o dossiê referente aos estudos dos feminismos e dos estudos de gênero, expostos ao Congresso Internacional "Femmes dans les Amériques", realizado em Aix-en-Provence, em dezembro de 2013 (CAPDEVILA, SORIN, 2014).

A perspectiva de fazer um estudo de análise Norte-Sul se coloca como importante no momento atual onde se percebe um interesse desta historiografia para com os estudos sobre os países do Cone Sul. Penso na historiografia como conhecimento temporário das narrativas sobre um tempo e, atualmente, o "tempo das ditaduras" vem atraindo a historiografia, especialmente com a possibilidade de pesquisa em arquivos que passaram a disponibilizar os acervos do período das ditaduras. Entendo que, de certa maneira, as contribuições teóricas no Eixo-Sul já vêm sendo investigados pela historiografia ${ }^{19}$, mas, em relação ao Norte-Sul pouco ainda temos

16 Comissão Nacional da Verdade. Lei n. 12.528, de 18 nov. 2011. Disponível em: http://cnv.memoriasreveladas.gov.br/institucional-acesso-informacao/a-cnv/56-conheca-a-lei-que-criou-acomissao-nacional-da-verdade.html Acesso em: 25/maio/2019.

17 Disponível em: http://nuevomundo.revues.org/66373 Acesso em: 25/maio/2019.

18 Ver, Capdevila, 2014.

19 Podemos dizer que de certa maneira as pesquisas desenvolvidas no Cone Sul já "circulam" entre as/os pesquisadoras/es, contribuindo com diferentes análises. Sobre esta perspectiva de circulação dos saberes 
problematizado e, vale lembrar, como destaca Joana Maria Pedro,

Na divisão internacional de produção teórica, costumeiramente, é no "Norte" que se constituem as teorias e no "Sul" que se fazem os estudos de caso. É o Norte quem dita qual teoria é mais importante e legítima, e qual é a menos "correta", a mais atrasada. A abordagem pós-estruturalista, por exemplo, excluiu do vocabulário teórico legítimo a categoria "mulher", acusando-a de ser essencialista. Entretanto, para as historiadoras do Cone Sul, as categorias "mulher" e "mulheres" continuam muito presentes. (2011)

Não pretendemos, evidentemente, ratificar que no Sul se fazem os estudos de caso, mas perceber como, na contemporaneidade, historiadores do Norte, notadamente a historiografia francesa, vem tematizando o período que compreende as ditaduras civismilitares vivenciadas no Cone Sul, especialmente Brasil, Paraguai, Chile e Argentina. Desta maneira, estas análises estão integradas às pesquisas que desenvolvemos no LEGH e dialogam com os debates contemporâneos, como alguns apresentados no "XXXVI Congresso Internacional da Associação de Estudos Latino-Americanos - LASA 2018: Estudos Latino-americanos en un Mundo Globalizado"20.

Como já dissemos, sobre o período das ditaduras no Cone Sul as mais diferentes temáticas vêm sendo pesquisadas. $\mathrm{E}$, em relação a uma análise a partir da historiografia francesa sobre o Cone Sul, algumas obras sobre o período que compreende as ditaduras civis-militares vivenciadas, especialmente Brasil, Paraguai, Chile e Argentina, nos chamam a atenção.

Atualmente estamos analisando algumas obras publicadas na França, visando perceber como esta historiografia vem tematizando (em uma perspectiva comparativa entre Norte e América do Sul) este período. Deste modo, trabalhamos com uma perspectiva da história comparada ou cruzada ${ }^{21}$, para pensar nestes países, bem como, com uma perspectiva transnacional, visando observar o trânsito de teorias Norte-Sul22. Todavia, convém destacar, que falar em história comparada não significa homogeneizar as diferentes ditaduras e, tão pouco, procurar conhecer as diferentes experiências a partir das mesmas questões. Mas, perceber as conexões entre as histórias destes diferentes países, pois, muitas vezes, são as experiências em comum, como exílio, tortura clandestinidade, entre outros, que são abordados por pesquisadores de outras regiões. Ou seja, não se trata de promover conexões globalizantes, mas perceber que os olhares transnacionais tematizam as histórias do Sul.

Também os estudos no campo da memória são importantes pois, tais reflexões, também nos ajudam a compreender como os estudos da memória a partir da realidade europeia vinculada à memória traumática da segunda Guerra ainda pautam as análises sobre as memórias do Cone Sul relacionado ao período traumático das ditaduras, embora alguns estudos apresentem novos argumentos ${ }^{23}$. Assim, as reflexões de Pierre Nora (1993), sobre os "lugares de memória", bem como, as de Paul Ricoeur (2007),

no Eixo-Sul, ver: Zucco, 2014

${ }^{20}$ Programação disponível em: https://lasaweb.org/lasa_archive/lasa2018_archive/index.aspx

21 Ver: Fausto, Devoto, 2004.

22 Recentemente várias/os autoras/es vem trabalhando com esta perspectiva, entre estes destaco: Glik, 2015; Ribeiro, 2000; e, Seigel, 2001.

${ }^{23}$ Refiro-me especialmente as reflexões de Beatriz Sarlo que, ao tratar o período pós-ditadura na Argentina menciona que: "O 'dever de memória' que o Holocausto impõe à história europeia foi acompanhado pela atenção dada às memórias dos sobreviventes e aos vestígios deixados pelas vítimas. Contudo, é preciso problematizar a extensão dessa hegemonia moral, sustentada por um dever de ressarcimento, feito sobretudo de memória" (2007, p. 43). 
tematizando a questão do perdão são importantes para perspectivar os acervos, os arquivos e a historiografia produzida. Citar estes autores é importante pois, de maneira geral, a influência destes autores para as reflexões sobre memória no Cone Sul é marcante. Ou seja, os aportes teóricos sobre memória provenientes da historiografia francesa marcam de maneira considerável as pesquisas realizadas no Cone Sul.

$E$, notadamente sobre a emergência de novas fontes a partir da abertura de arquivos sobre as ditaduras, e sobre as fontes relativas ao período presente em arquivos internacionais, penso ser importante estar atenta as múltiplas possibilidades de análise que estas podem propiciar para as discussões acerca da memória do tempo da ditadura, pois, como lembra Reinhart Koselleck, "Como historiadores, devemos dar um passo além, se quisermos fazer história de maneira consciente, ou se quisermos chamar 0 passado à memória" (2006, p. 186).

Investigar o que vem sendo pesquisado e publicado em outros países, como por exemplo a França, sobre as ditaduras no Cone Sul, é podemos dizer, um trabalho moroso. Até o momento, conseguimos realizar um levantamento das dissertações e teses defendidas em universidades francesas e as principais obras publicadas na França, disponíveis em bibliotecas, arquivos e centros de documentação, tais como: Bibliothéque de Documentation International Contemporaine, da Université Paris X; Biblioteca do CERHIO e da Université Rennes 2, em Rennes; Biblioteca Marguerite Durand, em Paris; Biblioteca Nacional, em Paris; Instituto de História do Tempo Presente (IHTP), em Paris; Centre d'Information et de Documentation Internationale Contemporaine, no Institut dês Hautes Etudes de l'Amerique Latine, em Paris; Pesquisa no Centre de Recherches sur le Brésil Colonial et Contemporain (CRBC/EHESS), em Paris.

A partir das referências bibliográficas pesquisadas, analisamos algumas obras sobre o Chile, Argentina e Brasil. De maneira preliminar podemos observar que são sobre Argentina e Chile que mais incidem trabalhos. Pesquisando o acervo da Bibliothéque de Documentation International Contemporaine, da Université Paris X, em Nanterre, França, por exemplo, ao pesquisar o acervo bibliográfico, é possível localizar muitas obras sobre o tema ditaturas nos países do Cone Sul, num total de 608 obras sobre ditaduras. O destaque é sobre a Argentina, 81 registros, mas, ao analisar as obras, a maioria foram publicadas na Espanha ou Argentina e foram doadas ao acervo da biblioteca francesa. O mesmo acontece com o Chile e o Brasil e, no caso deste, a maioria são obras de autores brasileiros que classicamente pesquisam a ditadura no Brasil e foram doados ao acervo da biblioteca. A mesma impressão temos ao pesquisar o acervo da Biblioteca Nacional da França, localizada em Paris. Ou seja, apesar de nos encontros acadêmicos, como por exemplo, o Congresso Internacional "Femmes dans les Amériques", realizado em Aix-en-Provence, em dezembro de 2013 e o "XXXVI Congresso Internacional da Associação de Estudos Latino-Americanos - LASA 2018: Estudos Latino-americanos en un Mundo Globalizado", realizado em Barcelona em 2018, citados anteriormente, a temática sobre as ditaturas sobre o Cone Sul estarem presentes, os resultados destas pesquisas ainda não foram amplamente publicizados. Esta constatação, de certa maneira, dificulta o olhar para os objetivos da pesquisa, mas, não inviabiliza a possibilidade de conhecer algumas possiblidades de análise.

Ainda, cabe ressaltar que, diferentemente de uma observação preliminar, não é necessariamente no campo da história que mais incidem pesquisas sobre as ditaduras do Cone Sul. Na sociologia, literatura e filosofia encontramos algumas obras dedicadas ao tema. Na literatura e filosofia, por exemplo, destaco a obra "La subversion passée 
sous silence”, da Argentina Gisele Amaya Dal Bó, publicado pela L'Harmattan, em 2018. A obra, trabalha a partir de uma perspectiva comparativa das políticas de memória estabelecidas no Chile e na Argentina, após as ditaduras dos anos 1970 (Dal Bó, 2018). Também, destaca-se que algumas obras sobre as ditaduras no Cone Sul publicadas por editoras francesas são livros de memórias, evidenciando narrativas sobre as memórias daquelas/es que vivenciaram as ditaduras.

$\mathrm{Na}$ história, podemos observar um crescimento destas pesquisas, como a recente tese defendida na Université Rennes 2, sobre a participação de "mulheres negras nos movimentos de esquerda durante a ditadura no Brasil" (Silva, 2019). Mas, como ainda são pesquisas em andamento ou recentemente finalizadas, ainda não estão publicadas. E, notadamente um outro aspecto importante a ser observado é o fato de que muitas pesquisas iniciadas na França sobre os países do Cone Sul partiram da iniciativa de pesquisadoras/es nascidos nos países do Cone Sul e que foram fazer sua formação acadêmica em França, como é o caso de Tauana Olívia Gomes Silva (2019) e de outras/os pesquisadoras/es argentinas/os e chilenas/os.

\section{Algumas publicações sobre os países do Cone Sul}

Após ler várias obras sobre as ditaduras no Cone Sul publicadas na França, a maioria não citadas neste texto, especialmente por não se tratar de publicações historiográficas, mas boa parte, memorialísticas, podemos observar que, diferente de muitas obras publicadas nos países do Cone Sul, como Brasil e Argentina, na historiografia francesa não localizamos muitas obras que articulam memória, gênero e ditaduras.

A maioria das obras realizam uma análise histórica sobre a ditadura estudada e, muitas vezes, aprofundam discussões no campo da memória. Diferente de países do Cone Sul, como o Brasil, onde já existe uma longa tradição de publicar sobre gênero ${ }^{24}$ e feminismos no Cone Sul, esta ainda é uma temática muito recente na historiografia francesa.

Mas, mesmo que timidamente, podemos apresentar algumas obras que indicam pistas de como a historiografia francesa vem tematizando as ditaduras do Cone Sul, sem necessariamente articular as três temáticas perscrutadas por esta pesquisa.

Sobre o Chile, destaco o livro "Politiques de genre et féminisme dans le Chili de la post-dictature", de Nicole Forstenzer (2012), publicado pela L'Harmattan, que apresenta, entre outros temas, o fluxo e refluxo do movimento feminista chileno e os impasses estratégicos do feminismo. A pesquisa da autora perspectiva o período pósditadura, mas, penso é importante ser analisada relacionada a temática pois, enfoca o Estado do Chile assumindo a responsabilidade pela transição democrática das reivindicações de igualdade de gênero das mulheres na segunda onda feminista da década de 1980. O livro, fruto de sua tese, examina o feminismo chileno e analisa as políticas de gênero do Estado, suas ressonâncias locais e internacionais, e seus efeitos nos conflitos que constituem as relações de gênero, nomeadas pela autora como "rapports sociaux de sexe" (FORSTENZER, 2012, p. 18). Ainda sobre o Chile, encontramos também alguns livros de memórias, publicados na França, narrando as histórias da ditadura chilena, como por exemplo, "Femmes et dictature: être chilienne sous Pinochet", organizado por Catherine Blaya (2000), que apresentou as narrativas

${ }^{24}$ Além dos trabalhos já citados, destaco também as obras de Susel Oliveira da Rosa (2013) e Luiza Margareth Rago (2013). 
de Miriam, Marcela, Maria Dolores, Ingrid e Alicia. Independente de serem obras, historiográficas ou não, este tipo de publicação vem ajudando a compreender como as ditaduras do Cone Sul são pesquisadas e publicadas em outros países.

Em relação à Argentina, a tese de Nadia Thair, defendida em 2011, na Université Paris Sorbonne - Paris IV e publicada sob o título "Argentine. Mémoires de la dictature" (THAIR, 2015), é um bom exemplo das pesquisas históricas realizadas recentemente. A autora estuda as associações de vitimas da última ditadura na Argentina (1976-1983), a partir de uma vasta documentação. Ao pesquisar a situação da Argentina, menciona que desde o fim da ditadura, a Argentina tem sido objeto de muito trabalho, tanto por pesquisadores argentinos como por estrangeiros. Associações de parentes dos desaparecidos e sobreviventes na Argentina são mencionadas em trabalhos sobre a ditadura e a oposição ao regime. A forma como narra o histórico das associações, entre elas a de familiares de presos e desaparecidos por razões políticas é minuciosa. Em seu trabalho evidencia a evolução cronológica e o desenvolvimento discursivos das associações e apresenta uma discussão teórica sobre o conceito de vítima no processo de construção da memória do passado recente da Argentina.

Sobre a ditadura brasileira, um trabalho bem conhecido na França é da historiadora Maud Chirio. Em "La politique en uniforme" (2016), a autora apresenta um extenso trabalho de pesquisa realizado a partir de uma vasta documentação, discutindo as características de um regime militar hierarquizado.

Ainda sobre o Brasil, outras duas obras merecem destaque: "1964 La dictature brésilienne et son legs" (GREEN; SCHPUN, 2018) e "Le Brésil territoire d'histoire" (ROLLAND; SANTOS; RODRIGUES, 2013). Nota-se que são duas obras coletivas onde a maioria das/os autoras/es são brasileiras/os. A primeira obra é sobre a ditadura brasileira abordando diferentes aspectos, entre eles, um capítulo sobre gênero: "La question du genre dans la clandestinité au Brésil (1960-1980): usages et mémoires”, de Joana Maria Pedro (2018). A segunda: também é uma obra coletiva, com vária/os autoras/es brasileiras/os, que tematizam diferentes temas da historiografia brasileira, divididos em quatro partes: historiografia política, historiografia econômica e social, historiografia cultural e historiografia das relações internacionais. Embora trabalhe com temas relacionados a gênero, ditadura, história oral e memória, não são textos que articulam as três categorias analisadas juntas e, sobretudo, estes capítulos foram escritos por pesquisadoras/es brasileiras/os, como Joana Maria Pedro (gênero), Daniel Aarão Reis filho (ditadura) e José Carlos Sebbe (história oral).

Estas obras, escritas a partir de uma vasta documentação, fontes primárias e impressas, testemunhos e muitas referências bibliográficas, nos possibilitam investigar como a historiografia francesa vem tematizando as histórias relacionadas às ditaduras civis-militares vivenciadas no Brasil, Chile e Argentina.

As obras acima citadas constituem-se num pequeno exemplo de como parte da historiografia francesa vem tematizando as ditaduras no Cone Sul. De maneira geral, podemos dizer que quando tratam de países do Cone Sul, as autoras citadas preocuparam-se em dar um panorama sobre os países, a situação econômica e um histórico detalhado das organizações ou associações que estavam pesquisando, destaco aqui especialmente o trabalho de Nadia Thair (2015). Nem sempre a preocupação com os estudos de gênero estava presente, mas, podemos dizer, tangenciaram de forma interseccional muitas análises, como por exemplo, o trabalho de Nicole Forstenzer (2012). 


\section{Considerações finais}

Analisar como estes estudos, principalmente no campo da memória, influenciam os estudos realizados no Cone Sul sobre memória, verdade, justiça, reparação e lugares de memória é um dos objetivos da pesquisa que ainda está em andamento. Deste modo, perceber a circulação de teorias dos estudos franceses que contribuem com as pesquisas sobre as ditaduras realizadas nestes países pode nos ajudar a lançar novos olhares para estas histórias e, possivelmente, conhecer novas metodologias, visando perceber as diferentes possibilidades e contribuições teóricas no Eixo-Sul e em relação ao Norte-Sul.

Ao mesmo tempo, podemos dizer que pesquisar as histórias das ditaduras no Cone Sul, de diferentes maneiras e, neste caso, procurando conhecer as análises produzidas em outros países, é uma maneira de mostrar a importância dos estudos sobre as ditaduras e nossa resistência ao avanço do conservadorismo e de um certo revisionismo. Precisamos lembrar que neste momento conservador, onde um populismo de direita ganha espaço, representado pela eleição de Bolsonaro - a memória da ditadura, uma questão sensível e historicamente mal resolvida - sofre o risco de novos abalos. Vemos com frequência o atual presidente e seus seguidores valorizarem antigos torturadores e minimizarem as atrocidades que violaram os direitos humanos durante a ditadura. Ao que tudo indica, as recomendações propostas pela Comissão Nacional da Verdade, entre elas a construção de um Museu da Memória, não será uma ação governamental.

Fazemos esta observação pois, cotidianamente, acompanhamos discursos que minimizam o caráter autoritário e repressivo do período da ditadura militar. Embora a barbárie da história recente esteja fartamente documentada, como por exemplo, no Relatório da CNV e publicada em diferentes obras, há um certo descrédito em relação às memórias daquelas/es que narram estas histórias, como fosse uma inversão semântica sobre o passado ${ }^{25}$. Se o testemunho - de vítimas e familiares - foi importante para no período pós-ditadura novas narrativas emergirem, acompanhamos abismadas/os alguns esforços em desacreditá-los. E sabemos, como nos lembra Paul Ricouer: "A autenticação do testemunho só será então completa após a resposta em eco daquele que recebe o testemunho e o aceita; o testemunho, a partir desse instante, está não apenas autenticado, ele está acreditado" (2007, p. 173). Estar atenta aos usos contemporâneos da memória sobre a ditadura e divulgar a produção historiográfica sobre o período é uma maneira de resistir ao avanço do conservadorismo.

\section{Referências}

BAUER, Caroline Silveira. Brasil e Argentina: ditaduras, desaparecimentos e políticas de memória. Porto Alegre: Medianiz, 2012.

BLAYA, Catherine (Org). Femmes et dictature: être chilienne sous Pinochet. Paris: ESF, 2000.

CALVEIRO, Pilar. La memoria en tanto espacio ético y político. In: HUFFSCHMID, Anne; DURÁN, Valeria (Ed.). Topografías conflictivas: memorias, espacios y ciudades em

25 Sobre esta questão, ver: Vecchi, Roberto. Os (re)usos do passado. Disponível em: http://www.buala.org/pt/a-ler/os-reusos-do-passado Acesso em: 25/maio/2019. 
disputa. Buenos Aires: Nueva Trilce, 2012, p. 21-30.

CAPDEVILA, Luc. Les travaux de la Commission Vérité et Justice, un tournant historiographique au Paraguay, Nuevo Mundo Mundos Nuevos Disponível em: http://nuevomundo.revues.org/66572 Acesso em: 25/maio/2015.

CAPDEVILA, Luc; SORIN, Claire. Histoire des féminismes, études de genre et des identités de genre dans les Amériques, $\mathrm{XIX}^{\mathrm{e}}$ et $\mathrm{XX}$ siècles, Nuevo Mundo Mundos Nuevos, Disponível em: http://journals.openedition.org/nuevomundo/66373 Acesso em: 25/maio/2019.

CHIRIO, Maud. La politique em uniforme: l'expérience brésilienne, 1960-1980. Rennes: Presses universitaires de Rennes, 2016.

CORTE SUPREMA DE JUSTICIA. Museo de la Justicia. Centro de Documentación y Archivo para la Defensa de los Derechos Humanos. Catálogo. Asunción, 2010.

CRISTIÁ, Moira. Imaginaire Péroniste

DAL BÓ, Gisele Amaya. La subversion passée sous silence: politiques de memóire sur la dictature en Argentine et au Chili. Paris: L'Harmattan, 2018.

FAUSTO, Boris; DEVOTO, Fernando J. Brasil e Argentina. Um ensaio de história comparada (1850-2002). São Paulo: Editora 34, 2004.

FICO, Carlos. Além do golpe: versões e controvérsias sobre 1964 e a ditadura militar. 3. ed. Rio de Janeiro: Record, 2014 a.

FICO, Carlos. O golpe de 1964: momentos decisivos. Rio de Janeiro: Editora da FGV, 2014 b.

FORSTENZER, N, Politiques de genre et féminisme dans le Chili de la post-dictature: 1990-2010. Paris: L'Harmattan, 2012.

GASPARI, Elio. A ditadura envergonhada. São Paulo: Companhia das Letras, 2002.

GLIK, Monica Sol. El hogar de la victoria: la promesa del American Way Of Life para América Latina (Estados Unidos, Argentina y Brasil (1940/1945). Florianópolis: UFSC; Madrid, Universidad Autónoma de Madrid, 2015 (Tese de Doutorado em História).

GREEN, J. N.; SCHPUN, M. R. (Org.). 1964: La dictature brésilienne et son legs. Paris: Le Poisson Volant, 2018.

JELIN, Elizabeth. Memorias de la Represión. Madrid: Siglo XXI Editores, em 12 volumes.

JOFFILY, Mariana. No centro da engrenagem: os interrogatórios na Operação Bandeirante e no DOI de São Paulo (1969-1975). São Paulo, 2008. (Tese Universidade de São Paulo).

KOSELLECK, Reinhart. Futuro passado. Contribuição à semântica dos tempos históricos. Rio de Janeiro: PUCRio, 2006.

NORA, Pierre. Entre memória e história - a problemática dos lugares, Projeto História, São Paulo, n. 10, p. 7-28, dez. 1993.

OBERTI, Alejandra. Qué le hace el género a la memoria? In: PEDRO, Joana Maria; 
WOLFF, Cristina Scheibe (Orgs). Gênero, feminismos e ditaduras no Cone Sul. Florianópolis: Mulheres, 2010, p. 13-30.

PADRÓS, Enrique Serra; BARBOSA, Vânia M; LOPEZ, Vanessa A.; FERNANDES, Ananda Simões (Orgs.). A Ditadura de Segurança Nacional no Rio Grande do Sul (19641985): História e Memória. Porto Alegre, 2014. (4 volumes).

PAZ, Alfredo Boccia; AGUILAR, Rosa Palau; SALERNO, Osvaldo. Paraguay: Los Archivos del Terror. Los papeles que resignificaron la memoria del stronsimo. Asunción, Museo de la Justicia, 2008.

PEDRO, Joana Maria. Relações de gênero como categoria transversal na historiografia contemporânea. Topoi, v. 12, n. 22, jan.-jun. 2011, p. 270-283.

PEDRO, Joana Maria. Narrativas do feminismo em países do Cone Sul (1960-1989). In: PEDRO, Joana Maria; WOLFF, Cristina Scheibe (Orgs). Gênero, feminismos e ditaduras no Cone Sul. Florianópolis: Mulheres, 2010, p. 115-137.

PEDRO, Joana Maria. La question du genre dans la clandestinité au Brésil (1960-1980): usages et mémoires. In: GREEN, J. N.; SCHPUN, M. R. (Org.). 1964: La dictature brésilienne et son legs. Paris: Le Poisson Volant, 2018 , p. $281-305$.

PEDRO, Joana Maria; WOLFF, Cristina Scheibe (Orgs). Gênero, feminismos e ditaduras no Cone Sul. Florianópolis: Mulheres, 2010.

PEDRO, Joana Maria; WOLFF, Cristina Scheibe; VEIGA, Ana Maria (Orgs). Resistências, gênero e feminismos contra as ditaduras no Cone Sul. Florianópolis: Mulheres, 2011.

QUADRAT, S. V. (Org.) Caminhos cruzados: história e memória dos exílios latinoamericanos no século XX. Rio de Janeiro: FGV, 2011.

RAGO, Luzia Margareth. A aventura de contar-se: feminismos, escrita de si e invenções de subjetividade. Campinas, SP: Editora da Unicamp, 2013.

REBOLLEDO, Loreto. Chilenas en el exilio. In: AGUIRRE, Sonia Montecino (Org.). Mujeres chilenas: fragmentos de una historia. Santiago del Chile: Catalonia, 2008, 537545.

RIBEIRO, G.L. A condição da transnacionalidade. In: RIBEIRO, Gustavo Lins. Cultura e política no mundo contemporâneo. Brasília: Editora UNB, 2000.

RICHARD, Nelly. Feminismo, género y diferencia (s). Santiago del Chile: Palinodia, 2008.

RICOEUR, Paul. A memória, a história, o esquecimento. Editora da UNICAMP, 2007.

RODEGHERO, C. S.; MONTENEGRO, A.; ARAUJO, M. P. Marcas da Memória: História Oral da Anistia no Brasil. Recife: Editora Universitária da UFPE, 2012.

ROLLAND, D.; SANTOS; M.J.F; RODRIGUES, S. (Orgs.). Le Brésil territoire d'histoire: historiographie du Brésil contemporain. Paris: L'Harmattan, 2013.

ROSA, Susel Oliveira da. Mulheres, ditaduras e memórias: "Não imagine que precise ser triste para ser militante". São Paulo: Intermeios, Fapesp, 2013. 
SANTOS, C. MacDowell; TELES, Edson; TELES, Janaína de Almeida (Orgs.) Desarquivando a Ditadura: Memória e justiça no Brasil. São Paulo: Editora Hucitec, v.1v.2, 2009.

SAPRIZA, Graciela. Memoria e memorias de mujeres en el relato de la ditadura (Uruguay, 1973-1985). In: PEDRO, Joana Maria. Narrativas do feminismo em países do Cone Sul (1960-1989). In: PEDRO, Joana Maria; WOLFF, Cristina Scheibe (Orgs). Gênero, feminismos e ditaduras no Cone Sul. Florianópolis: Mulheres, 2010, p. 94-114.

SARLO, Beatriz. Tempo passado: cultura da memória e guinada subjetiva. São Paulo: Companhia das Letras; Belo Horizonte: UFMG, 2007.

SEIGEL, M. Beyond Compare: Comparative Method after the Transnational Turn, Radical History Review, 91, p. 62-90; 2005.

SILVA, Janine Gomes da; PEDRO, Joana Maria; WOLLF, Cristina Scheibe. Acervo de pesquisa, memórias e mulheres: o Laboratório de Estudos de Gênero e História e as ditaduras do Cone Sul. Revista do Instituto de Estudos Brasileiros, v. 71, p. 193-210, 2018. ISSN/ISBN: 2316901X - Disponível em: http://www.scielo.br/pdf/rieb/n71/2316901X-rieb-71-00193.pdf. Acesso em: 25/maio/2019.

SILVA, Tauana Olívia Gomes. Mulheres negras nos movimentos de esquerda durante a ditadura no Brasil (1964-1985). Rennes; Florianópolis: Université Rennes 2; UFSC, 2019 (Tese de Doutorado em História).

THAIR, Nadia. Argentine. Mémoires de la dictature. Rennes: Presses universitares de Rennes, 2015.

TOLER, A.A. Tense and tender ties: The politics of comparison in North American history and (post) colonial studies, The Journal of American History, v.88, n.3, 2001.

VERA, Myrian Gonzáles. Los Archivos del Terror del Paraguay. La historia oculta de la represión. In: CATELA, Ludmila da Silva; JELIN, Elizabeth (Orgs). Los Archivos de la represión: documentos, memoria y verdad. Madri: Siglo XXI de Espanã Editores, 2002, p. 85-114.

ZUCCO, Maise Caroline. Viagens e permanências dos Feminismos: o trânsito dos saberes no eixo sul do conhecimento (Brasil e Argentina 1960-1999), Florianópolis: UFSC, 2014 (Tese de Doutorado em História).

\section{Notas de autoria}

Janine Gomes da Silva é professora do Departamento de História, do Programa de PósGraduação em História e do Programa de Pós-Graduação em Ensino de História (ProfHistória), da Universidade Federal de Santa Catarina - UFSC. Doutora em História pela Universidade Federal de Santa Catarina (2004), com pós-doutorado na Universidade de Rennes 2, França (2017). É também pesquisadora do LEGH Laboratório de Estudos de Gênero e História e do IEG - Instituto de Estudos de Gênero. E-mail para contato: janine.gomesdasilva@gmail.com.

\section{Como citar esse artigo de acordo com as normas da revista}

SILVA, Janine Gomes da. Relações de gênero e memórias das ditaduras civis-militares: perspectivas da historiografia francesa sobre o Cone Sul. Sæculum - Revista de História, v. 24, nº 41, p. 161-175, 2019. 
Contribuição de autoria

Não se aplica.

Financiamento

Projeto de pesquisa financiado pelo CNPq.

Consentimento de uso de imagem

Não se aplica.

Aprovação de comitê de ética em pesquisa

Não se aplica.

Licença de uso

Este artigo está licenciado sob a Licença Creative Commons CC-BY. Com essa licença você pode compartilhar, adaptar, criar para qualquer fim, desde que atribua a autoria da obra.

Histórico

Recebido em 23/05/2019.

Aprovado em 01/10/2019. 